\title{
Nematicidal effects of cysteine proteinases against sedentary plant parasitic nematodes
}

\author{
G. STEPEK ${ }^{1}$, R. H. C. CURTIS ${ }^{2 *}$, B. R. KERRY ${ }^{2}$, P. R. SHEWRY ${ }^{2}$, S. J. CLARK ${ }^{2}$, \\ A. E. LOWE ${ }^{1}$, I. R. DUCE ${ }^{1}$, D. J. BUTTLE ${ }^{3}$ and J. M. BEHNKE ${ }^{1}$ \\ ${ }^{1}$ School of Biology, University of Nottingham, Nottingham NG7 2RD, UK \\ ${ }^{2}$ Rothamsted Research, Harpenden, Herts AL5 2FQ, UK \\ ${ }^{3}$ Academic Unit of Molecular Medicine, University of Sheffield, Sheffield S10 2RX, UK
}

(Received 25 May 2007; revised 5 Fune 2007; accepted 5 Fune 2007; first published online 19 Fuly 2007)

SUMMAR Y

Cysteine proteinases from the fruit and latex of plants, such as papaya, pineapple and fig, have previously been shown to have substantial anthelmintic efficacy, in vitro and in vivo, against a range of animal parasitic nematodes. In this paper, we describe the in vitro effects of these plant extracts against 2 sedentary plant parasitic nematodes of the genera Meloidogyne and Globodera. All the plant extracts examined caused digestion of the cuticle and decreased the activity of the tested nematodes. The specific inhibitor of cysteine proteinases, E-64, blocked this activity completely, indicating that it was essentially mediated by cysteine proteinases. In vitro, plant cysteine proteinases are active against second-stage juveniles of M. incognita and M. javanica, and some cysteine proteinases also affect the second-stage juveniles of Globodera rostochiensis. It is not known yet whether these plant extracts will interfere with, or prevent invasion of, host plants.

Key words: plant parasitic nematodes, Meloidogyne spp., Globodera rostochiensis, plant cysteine proteinases, in vitro, nematicide.

\section{INTRODUCTION}

Sedentary plant parasitic nematodes of the genera Meloidogyne and Globodera cause US\$70 billion in crop losses worldwide each year, despite the use of control measures (Chitwood, 2003). Although there are several ways to manage these nematode pests in developed agricultural systems, protection relies on the use of crop rotation, resistant cultivars and the use of nematicides. Chemical control is expensive and is economically viable only on high value crops, and public health and environmental safety concerns over the use of these pesticides have led to the withdrawal of several products from the market (Chitwood, 2003; Meyer, 2003). The loss of effective nematicidal chemicals has therefore increased the need for novel methods of nematode management.

Natural products with nematicidal properties have been identified by testing the effect of plant extracts (from leaves, stems, fruits and seeds), oil extracts, plant exudates and plant volatiles on nematodes that infect plants (Akhtar and Mahmood, 1994). Chopped shoots and plant extracts from plants, such

* Corresponding author: Division of Plant Pathogen Interactions, Rothamsted Research, Harpenden, Herts AL5 2JQ, UK. Tel: 441582763133 2437. Fax: 441582 760 981. E-mail: rosane.curtis@bbsrc.ac.uk

$\S$ Current address: Institute of Comparative Medicine, Faculty of Veterinary Medicine, University of Glasgow, Glasgow G61 1QH, UK. as papaya (Carica papaya), fig (Ficus carica), pineapple (Ananas comosus), frangipani (Plumeria rubra) and milkweed (Asclepias syriaca), were shown to be nematicidal to migratory endoparasitic nematodes and to reduce infection of plants (Siddiqui et al. 1992; Ahmad et al. 2004). However, the mode of action of most of these nematicidal extracts is unknown and the rates of application of most plant materials are too high to be widely used in practice.

For centuries, the use of natural plant extracts for the treatment of gastrointestinal (GI) nematode infections of both humans and livestock has been part of traditional medicine worldwide, especially in developing countries (Giday et al. 2003). Of these plant extracts, the most studied appear to be those from the latex and fruit of plants such as papaya (C.papaya), fig (Ficus spp.) and pineapple (A. comosus). Extracts from papaya have been used against ascarids, tapeworms, whipworms and hookworms (Berger and Asenjo, 1940). Although the active constituent was not determined until much later, Robbins (1930) indicated that the mechanism of action of these extracts was to digest the cuticle. The latex of fig (Sgarbieri et al. 1964) and papaya (Dubois et al. 1988), and the fruit of pineapple (Rowan et al. 1990) and kiwi (Actinidia chinensis; McDowall, 1970) are known to contain proteolytic enzymes of the papain family of cysteine proteinases (subfamily C1A of Family $\mathrm{C} 01$ in the Merops database: http://merops. 
sanger.ac.uk/), such as papain from $C$. papaya, ficin from Ficus spp. and bromelain from A. comosus. Our previous studies, examining the in vitro and in vivo effects of the cysteine proteinases from papaya, fig, pineapple and kiwi fruit against 3 rodent GI nematodes, Heligmosomoides polygyrus in the small intestine (Stepek et al. 2005), Trichuris muris in the caecum (Stepek et al. 2006) and Protospirura muricola in the stomach (Stepek et al. 2007), found that the active constituents were the cysteine proteinases, and that these enzymes from papaya, pineapple and fig, but not from kiwi fruit, had a rapid detrimental effect on the cuticle, which was completely digested, leading to the death of all 3 nematode species. Previous studies on plant nematodes by Miller and Sands (1977) showed that the migratory ectoparasite Tylenchorhynchus dubius was more susceptible to papain and bromelain than the migratory endoparasite Pratylenchus penetrans, suggesting that there may be significant differences between these 2 nematodes.

In view of these studies, we were interested to determine whether the mechanism of action of plant cysteine proteinases would be the same against 2 species of sedentary plant parasitic nematodes, principally in order to ascertain whether knowledge of the mode of action of these plant products would identify interactions with opportunities for the management of these nematodes.

MATERIALS AND METHODS

\section{Nematodes}

Eggs of $M$. incognita race 1 from North Carolina State University, USA, and $M$. javanica from Portugal were collected from the roots of infected tomato plants grown in a glasshouse at $23{ }^{\circ} \mathrm{C}$ in a $16: 8 \mathrm{~h}$ light-dark regime. Eggs were extracted using $1 \%$ hypochlorite $(\mathrm{NaClO})$ solution (Hussey and Barker, 1973) or by picking egg masses from the infected roots. M. incognita and $M$. javanica were both used in the experiments and produced similar results. Second-stage juveniles (J2) were hatched from the eggs and egg masses in water. Globodera rostochiensis cysts were washed extensively and soaked in distilled water; hatched J2s were obtained by incubating the cysts in potato root diffusate (PRD).

\section{Enzymes}

The enzymes used during this study were pure papain from the papaya plant (Carica papaya) (Merops identifier C01.001; Sigma catalogue number P3125), crude latex from papaya (C.papaya) (Sigma catalogue number P3250; lot number 124K1004), stem bromelain from the stem of the pineapple plant (Ananas comosus) (Merops identifier C01.005; Hong Mao Biochemicals Company,
Thailand), and actinidain from acetone precipitation of kiwi fruit juice (Actinidia chinensis; Merops identifier C01.007). These enzyme preparations were standardized for the molar concentration of active cysteine proteinase by titration with the cysteine proteinase-specific inhibitor, L-trans-epoxysuccinylleucylamido(4-guanidino)butane (E-64) (Sigma catalogue number E3132) (Stepek et al. 2005).

\section{In vitro assessment of the activity of plant cysteine proteinases against plant parasitic nematodes}

$\mathrm{J} 2 \mathrm{~s}$ of $M$. incognita or $M$. javanica were incubated per well of a 48-well plate with the following active concentrations (determined by E-64 titration) of papain dissolved in distilled water containing $16 \mathrm{mM}$ L-cysteine (to activate the cysteine proteinase): $1 \cdot 5 \mu \mathrm{M}, 3 \mu \mathrm{M}, 6 \cdot 25 \mu \mathrm{M}, 12 \cdot 5 \mu \mathrm{M}, 25 \mu \mathrm{M}, 50 \mu \mathrm{M}, 75 \mu \mathrm{M}$ and $100 \mu \mathrm{M}$. Control wells contained J2s and distilled water with and without $16 \mathrm{~mm}$ L-cysteine, or J2s and $1 \mathrm{~mm}$ E-64, with and without $50 \mu \mathrm{M}$ (active enzyme) papain; the E-64 and papain were pre-incubated for $25 \mathrm{~min}$ at $40{ }^{\circ} \mathrm{C}$ prior to the addition of the J2s. Each enzyme concentration and the controls were set up in duplicate $(n=2)$ or triplicate $(n=3)$. The number of active $\mathrm{J} 2 \mathrm{~s}$ per well was counted prior to the addition of papain, and then the J2s were incubated in the dark at room temperature for $3 \mathrm{~h}$. The number of motile J2s per well was counted after 60, 120 and $180 \mathrm{~min}$. The nematode surfaces were examined for signs of damage using a light microscope (Zeiss Axioskop) at $\times 20, \times 40$ and $\times 100$ magnification and photographs were taken with a Xillix Microimager. The same procedure was followed when setting up further experiments to compare the effects of $25 \mu \mathrm{M}$ papain, $25 \mu \mathrm{M}$ crude papaya latex $(0.625 \mathrm{~g} / \mathrm{ml}), 25 \mu_{\mathrm{M}}$ stem bromelain $(0 \cdot 18 \mathrm{~g} / \mathrm{ml})$ and $25 \mu \mathrm{M}$ actinidain (active enzyme concentrations) with $M$. incognita, $M$. javanica or G. rostochiensis.

The effects on the $\mathrm{J} 2$ cuticle were more closely examined by scanning electron microscopy (SEM). Approximately $2000 \mathrm{~J} 2 \mathrm{~s}$ were used per enzyme or control treatment. These J2s were added to each of four $5 \mathrm{ml}$ tubes and centrifuged at $1000 \mathrm{~g}, 4{ }^{\circ} \mathrm{C}$ for $5 \mathrm{~min}$. The supernatant was removed and the J2s were resuspended with $500 \mu \mathrm{l}$ of $100 \mu \mathrm{M}$ papain, $100 \mu \mathrm{M}$ actinidain (active enzyme concentrations) or distilled water with and without $16 \mathrm{~mm}$ L-cysteine (the enzyme dilutions were prepared with $16 \mathrm{mM}$ L-cysteine dissolved in distilled water). The nematodes were incubated in the dark at ambient temperature for $4 \mathrm{~h}$ before centrifugation as above. The J 2 s were immediately fixed with $2.5 \%$ glutaraldehyde in $0 \cdot 15 \mathrm{M}$ phosphate buffer, $\mathrm{pH} 7 \cdot 2$ for $1 \mathrm{~h}$ at room temperature and were then centrifuged as before prior to washing for $1 \mathrm{~h}$ in $0 \cdot 15 \mathrm{M}$ phosphate buffer, $\mathrm{pH} 7 \cdot 2$ at $4{ }^{\circ} \mathrm{C}$. These $\mathrm{J} 2 \mathrm{~s}$ were then prepared for SEM as described previously by Stepek et al. (2005). 
A

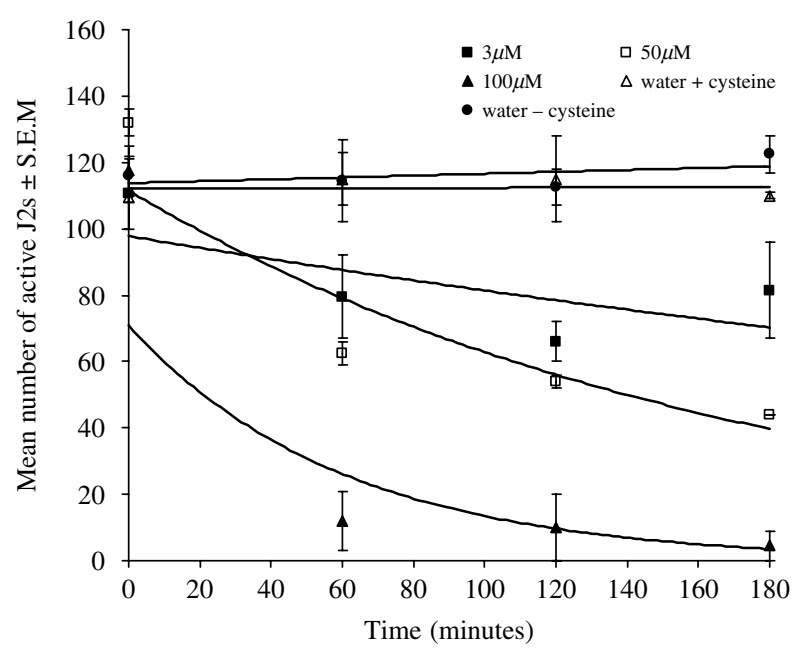

B

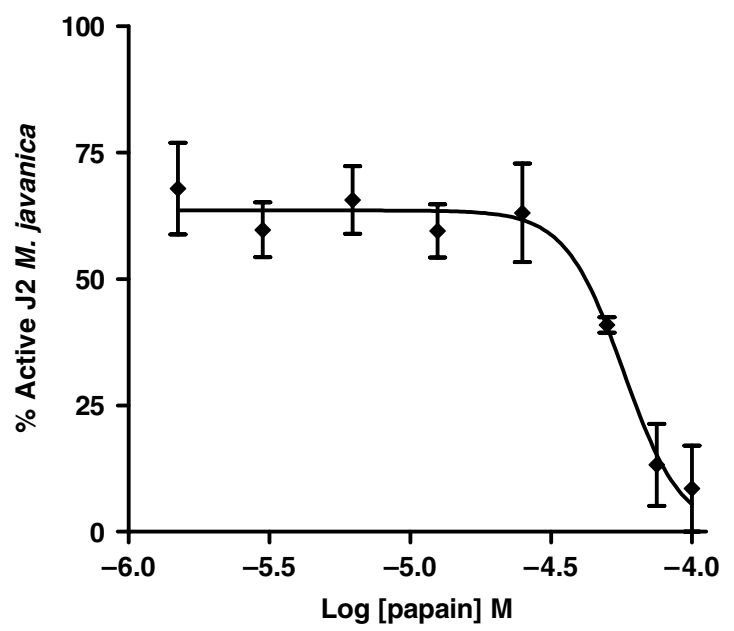

Fig. 1. The number of active Meloidogyne javanica J2s after exposure to increasing active enzyme concentrations of papain. (A) The number of active worms decreased as the papain concentration increased, while no change in activity was evident for the worms incubated in distilled water, with and without cysteine. Only 3 concentrations of papain ( $3 \mu \mathrm{M}, 50 \mu \mathrm{M}$ and $100 \mu \mathrm{M})$ are shown for clarity. Error bars represent the standard error of the mean. (B) A dose-response curve at $120 \mathrm{~min}$ indicating that as the concentration of papain increased, the number of active J2s decreased. $\mathrm{EC}_{50}=57 \mu \mathrm{M}$ (95\% confidence limits : $50 \cdot 3 \mu \mathrm{M}$ to $64 \cdot 9 \mu \mathrm{M}$ ). Error bars represent the standard error of the mean.

To assess whether these enzymes also affected the cuticles of other nematode stages, 5 adult females of $M$. incognita were incubated in wells of a 48 -well plate containing $25 \mu \mathrm{M}$ (active enzyme) papain in phosphate-buffered saline (PBS), $\mathrm{pH} 7 \cdot 4$, containing $16 \mathrm{~mm}$ L-cysteine, or PBS alone, with and without $16 \mathrm{~mm}$ L-cysteine. These nematodes were incubated in the dark at ambient temperature for $4 \mathrm{~h}$ and were then examined using a light microscope at $\times 10$ and $\times 20$ magnification to observe any changes to the nematode body wall.
To determine if the enzymes affected the eggshell and/or the development and hatching of the juveniles which the eggs contain, approximately 300 Meloidogyne spp. eggs were incubated per well of a 48 -well plate, in duplicate, in $50 \mu_{\mathrm{M}}$ (active enzyme) papain in distilled water containing $16 \mathrm{~mm}$ L-cysteine, or distilled water with and without $16 \mathrm{~mm}$ L-cysteine. The number of eggs in each well was counted before the addition of papain and then the eggs were incubated in the dark at room temperature for $4 \mathrm{~h}$. The number of eggs was counted before further incubation overnight. Finally, closer examination of the structure of the nematode eggs was performed using the light microscope at $\times 40$ magnification.

\section{Statistics}

The data from the in vitro motility experiments were analysed using a repeated measures analysis of variance (as implemented in the GenStat procedure AREPMEASUREMENTS) to compare the overall treatment means, the overall means at each sample time, and the treatment by time interaction. Numbers of nematodes moving at each of the repeated sampling times, 60, 120 and $180 \mathrm{~min}$, were expressed as a proportion of those moving initially at time 0 (i.e. this latter number was assumed to be the actual number of nematodes initially in the dish). The proportions were transformed to logits prior to analysis. A small adjustment $(p=(r+0 \cdot 5) /(n+1)$, where $r$ is the number moving at a given time and $n$ is the number moving at time 0) was made to all the data prior to transformation to allow for occurrences of $100 \%$. Degrees of freedom were partitioned to explore particular treatment comparisons and trends, and were adjusted before testing the main effect of time and interaction terms to allow for unequal patterns of correlation due to the repeated nature of measurements on wells. For Fig. 1B, a sigmoidal dose-response curve was fitted in GraphPad Prism (version 4), and the $\mathrm{EC}_{50}$ was calculated together with $95 \%$ confidence limits (CL).

\section{RESULTS}

\section{Effect of plant cysteine proteinases on the motility} of Meloidogyne $s p p \cdot \mathcal{F} 2 s$

Nematode motility was similar for the 2 controls (nematodes in distilled water, with and without cysteine; $\left.F_{1,10}=0 \cdot 02, P=0 \cdot 886\right)$, which was consistent over time $\left(F_{1 \cdot 5,14 \cdot 7}=3 \cdot 57, P=0 \cdot 066\right)$. The control nematodes had a normal appearance. Addition of papain (data for all doses combined) decreased the motility of Meloidogyne spp. J2s compared to the combined controls $\left(F_{1,10}=65 \cdot 1, P<0 \cdot 001\right)$. As the concentration of papain increased, the proportion of motile J2s of Meloidogyne spp. decreased linearly $\left(F_{1,10}=14 \cdot 0, P=0 \cdot 004\right)$ (Fig. $1 \mathrm{~A}$; the data for only 3 concentrations is shown for clarity), and the linear 

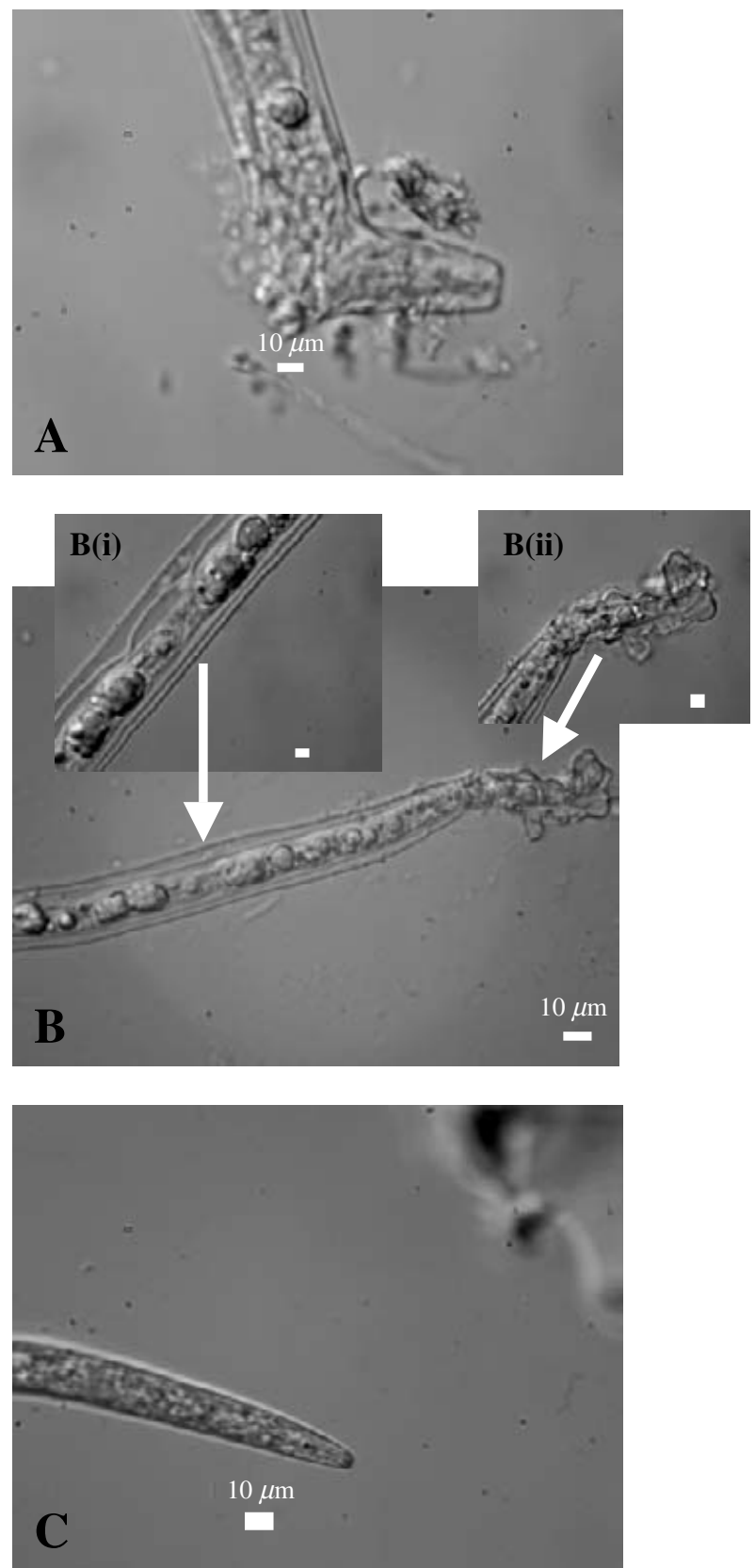

Fig. 2. Light micrographs of Meloidogyne incognita J2s incubated with and without papain for $3 \mathrm{~h}$. Digestion of the cuticle was evident at the anterior end of the nematodes incubated with $6 \cdot 25 \mu \mathrm{M}$ (A) and $100 \mu \mathrm{M}$ (Bii) (active enzyme) papain. The J2s incubated with $100 \mu \mathrm{M}$ papain (Bi) also showed an abnormal granular appearance of the internal structures. The J2s incubated without enzyme (C) had a normal appearance.

decrease in motility with increasing dose was similar regardless of how long the nematodes were incubated (time $\times$ dose: $\left.F_{1 \cdot 5,14 \cdot 7}=0 \cdot 5, P=0 \cdot 558\right)$. Fig. $1 \mathrm{~B}$ shows the dose-response relationship at $120 \mathrm{~min}$ (similar curves were obtained at $60 \mathrm{~min}$ and $180 \mathrm{~min})$. The $\mathrm{EC}_{50}$ value at $120 \mathrm{~min}$ was $57 \mu \mathrm{M}(95 \%$ confidence limits: $50 \cdot 3 \mu \mathrm{M}-64.9 \mu \mathrm{M})$. Damage to the nematode surface also increased. Papain at active enzyme concentrations of $1 \cdot 5 \mu \mathrm{M}$ and $3 \mu \mathrm{M}$ caused reductions in the activity of Meloidogyne J2s (e.g. $1 \cdot 5 \mu \mathrm{M}$ : $\left.\mathrm{t}_{16}=2 \cdot 99, P<0 \cdot 001\right)$ relative to the combined controls, but there were no visible effects on the surface of the nematodes. Only active enzyme concentrations above $6 \cdot 25 \mu$ M caused blistering of the cuticle, visible at $\times 40$ and $\times 100$ magnifications, at the anterior end of the nematode, and an abnormal granular appearance of the internal structures (Fig. 2).

\section{Plant cysteine proteinases damage the surface of Meloidogyne $s p p . \mathcal{F} 2 s$}

The surface damage observed with light microscopy was examined more closely using SEM. The surface cuticle of the J2s incubated with papain (Fig. 3A) and actinidain (Fig. 3B) had been digested, compared to those $\mathrm{J} 2 \mathrm{~s}$ not exposed to any enzyme (Fig. 3C), which retained a distinct cuticle layer (Fig. 3Cii). This layer had disappeared after incubation for $4 \mathrm{~h}$ with either papain (Fig. 3Aii) or actinidain (Fig. 3Bii).

\section{Effect of co-incubation of plant cysteine proteinases} with the cysteine proteinase-specific inhibitor, E-64, on the motility of Meloidogyne spp. $\mathcal{F} 2 s$

During this experiment, $50 \mu \mathrm{M}$ (active enzyme) papain was used because, from the dose response data, the $\mathrm{EC}_{50}$ value at $60 \mathrm{~min}$ or $120 \mathrm{~min}$ was approximately $50 \mu \mathrm{M}$. None of the 115 nematodes $(n=3$, mean $=38 \cdot 3)$ treated with papain alone were motile after $180 \mathrm{~min}$, whereas all of the 111 nematodes $(n=3$, mean $=37)$ treated with papain preincubated with the inhibitor, E-64, and all of the 106 nematodes $(n=3$, mean $=35 \cdot 3)$ treated with only water and cysteine were still motile after this time (Fig. 4). This shows that there was an overall reduction in nematode motility when treated with papain compared to no papain, but there was no reduction in the motility of those nematodes exposed to papain which had been pre-incubated with the cysteine proteinase-specific inhibitor, E-64. Thus, the effects on the number of active worms and on the nematode surface were dependent upon the activity of the cysteine proteinases.

The nematicidal effect was not only caused by papain (Fig. 5) as a significant reduction $\left(F_{1,4}=47 \cdot 09\right.$, $P=0.002)$ in the proportion of active nematodes relative to the control was also evident for the J2s incubated with papaya latex (which contains 3 additional cysteine proteinases as well as papain) and stem bromelain (combined data). No differences in motility were observed amongst the 3 enzyme preparations when used at the same active enzyme concentration $\left(25 \mu \mathrm{M} ; F_{2,4}=4 \cdot 83, P=0.086\right)$.

\section{Effect of plant cysteine proteinases on the motility of $\mathrm{G}$. rostochiensis $\mathcal{Z} 2 \mathrm{~s}$}

When $\mathrm{J} 2 \mathrm{~s}$ were incubated without these enzymes, there was no significant reduction in the number of 

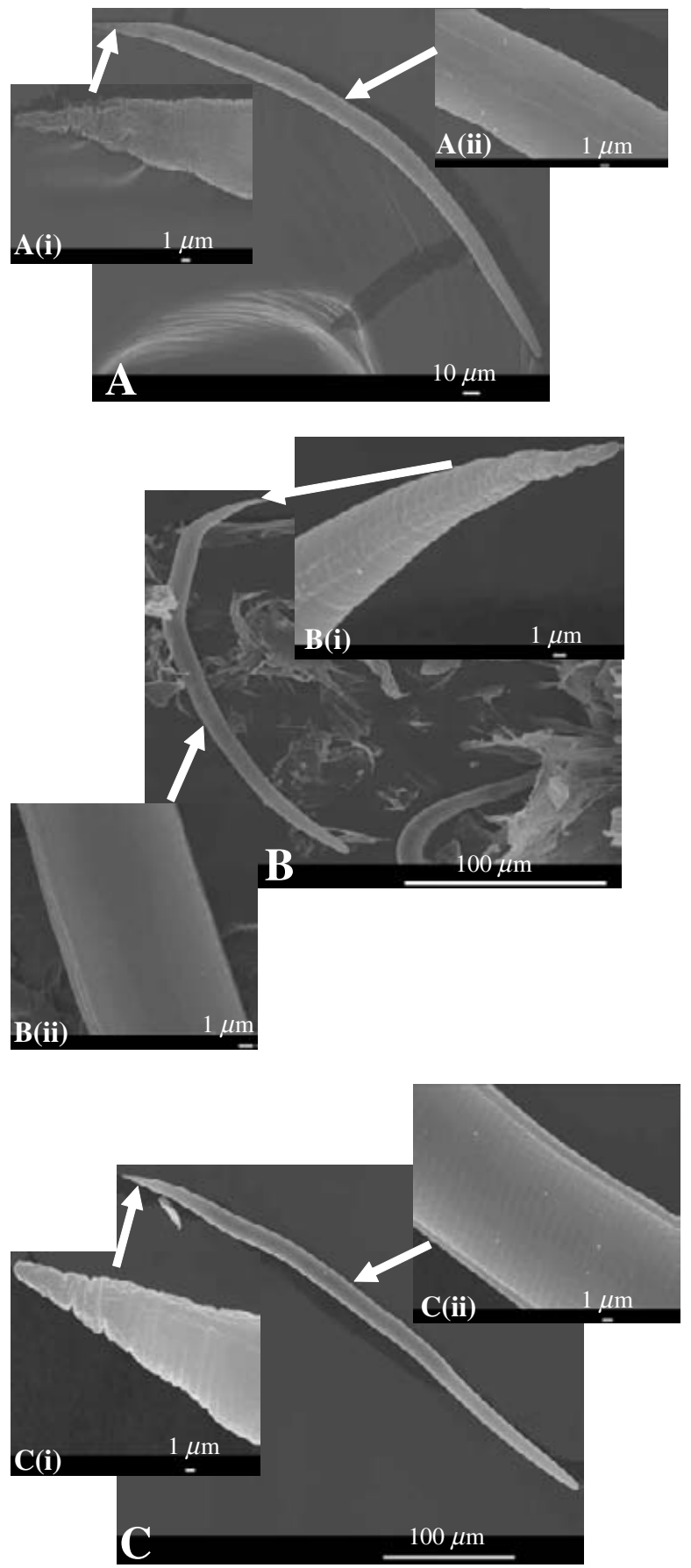

Fig. 3. Scanning electron micrographs of Meloidogyne incognita $\mathrm{J} 2 \mathrm{~s}$ exposed to papain or actinidain for $4 \mathrm{~h}$. Digestion of the cuticle was evident for the J2s incubated with $100 \mu \mathrm{M}$ (active enzyme) papain (Ai) and $100 \mu \mathrm{M}$ (active enzyme) actinidain (Bi), but not for those incubated without enzyme (C). Note the absence of a distinct cuticular layer in the $\mathrm{J} 2 \mathrm{~s}$ incubated with papain (Aii) and actinidain (Bii), compared to J2s incubated without enzyme (Cii).

active worms. The effects of papaya latex and papain on the motility of $G$. rostochiensis were similar to each other $\left(F_{1,4}=1 \cdot 96, P=0 \cdot 234\right)$. The effect of stem bromelain, on the other hand, was similar to the controls $\left(F_{1,4}=2 \cdot 61, P=0 \cdot 181\right)$. When the data for papain and papaya latex were combined, the

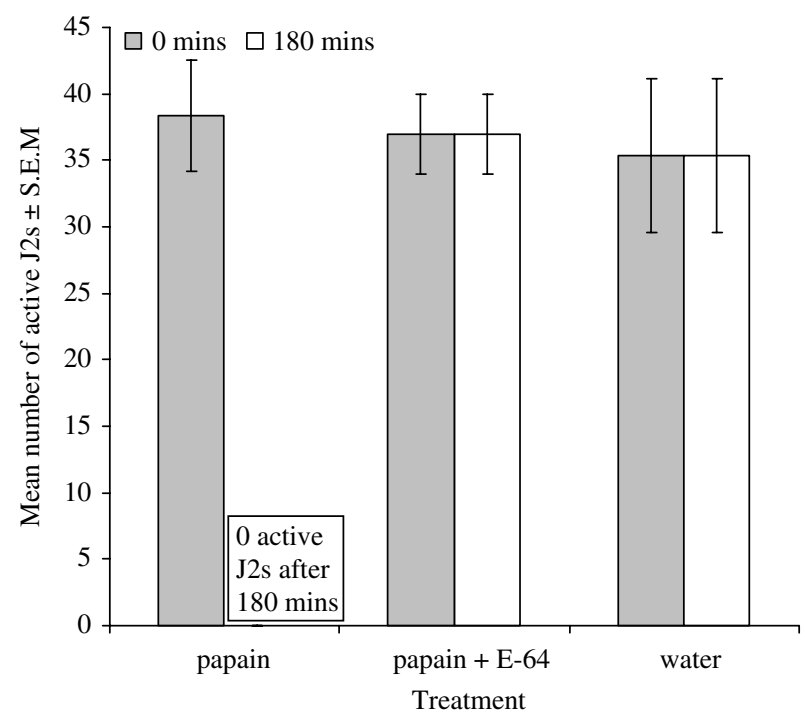

Fig. 4. The number of active Meloidogyne incognita J2s after exposure to $50 \mu \mathrm{M}$ (active enzyme) papain, with and without the cysteine proteinase-specific inhibitor, E-64 $(1 \mathrm{~mm})$. A difference in the proportion of active worms was observed between the $\mathrm{J} 2 \mathrm{~s}$ incubated with papain and the J2s incubated with papain which had been preincubated with E-64. No change in the proportion of active worms was evident on the addition of E-64 for J2s incubated without enzyme (data not shown). Error bars represent the standard error of the mean.

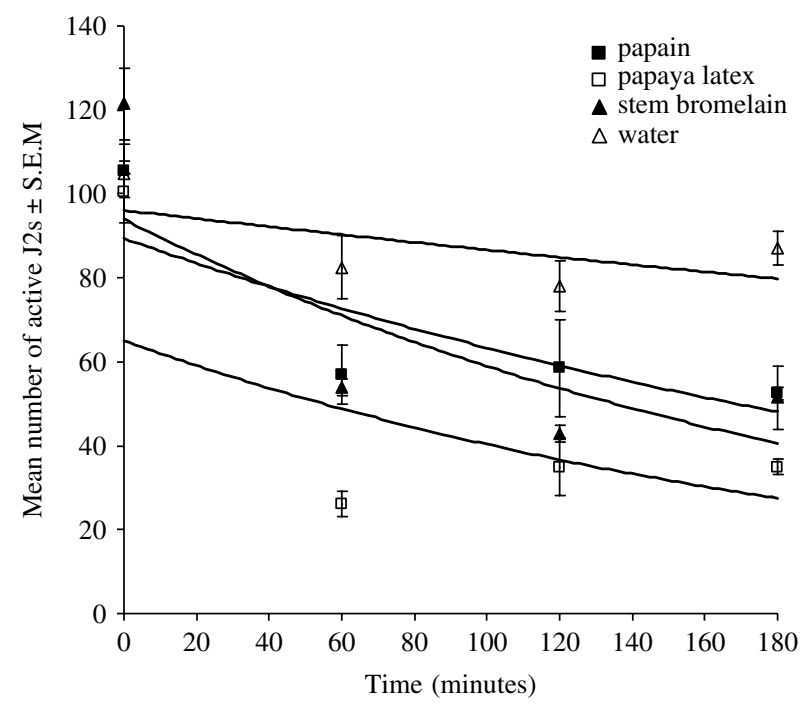

Fig. 5. The number of active Meloidogyne javanica J2s after exposure to $25 \mu \mathrm{M}$ (active enzyme) papain, $25 \mu \mathrm{M}$ (active enzyme) papaya latex and $25 \mu \mathrm{M}$ (active enzyme) stem bromelain. Reductions in the proportion of active worms were evident for the J2s incubated with papain, papaya latex and stem bromelain, but not for the J2s incubated without enzyme. Error bars represent the standard error of the mean.

reduction in motility was significantly greater overall than the control and stem bromelain combined $\left(F_{1,4}=17 \cdot 50, P=0 \cdot 014\right)$ (Fig. 6), and there was some evidence that this effect increased with time $\left(F_{1 \cdot 3,5 \cdot 1}\right.$ $=6.89, P=0 \cdot 043)$. In comparison to Meloidogyne 


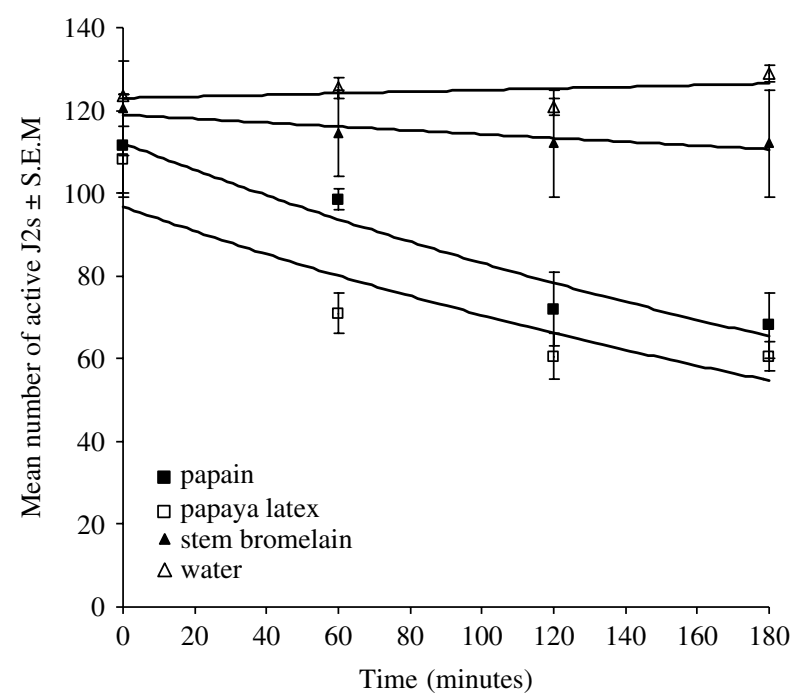

Fig. 6. The number of active Globodera rostochiensis J2s after exposure to $25 \mu \mathrm{M}$ (active enzyme) papain, $25 \mu \mathrm{M}$ (active enzyme) papaya latex and $25 \mu \mathrm{M}$ (active enzyme) stem bromelain. Reductions in the proportion of active worms were evident for the J2s incubated with papaya latex and papain, but not with stem bromelain or for those J2s incubated without enzyme. Error bars represent the standard error of the mean.

spp., G. rostochiensis J2s needed longer incubation periods with papain and papaya latex before any damage to their cuticle occurred (data not shown).

\section{Effect of plant cysteine proteinases on Meloidogyne spp. adult female worms}

When adult females of $M$. incognita were incubated with $50 \mu \mathrm{M}$ (active enzyme) papain, digestion of the cuticle was evident (Fig. 7A). Again, the cuticle of the females incubated with papain differed from that of the worms incubated without enzyme (Fig. 7B) in that the cuticle separated from the nematode after incubation with enzyme, and this cuticle digestion eventually led to the release of the internal structures from these nematodes.

Although the above results demonstrate that plant cysteine proteinases have a nematicidal effect against the $\mathrm{J} 2 \mathrm{~s}$ and adult worms of sedentary plant parasitic nematodes, these same enzymes had no apparent effect against the eggs of Meloidogyne spp. (results not shown). With light microscopy, examination of the structure of the eggs indicated that they had not been affected. Also, hatching and development of the J2 stage within the egg was not affected by incubation of the eggs with plant cysteine proteinases, such as papain.

\section{ISCUSSION}

This study showed that, in vitro, cysteine proteinases from papaya, pineapple and kiwi fruit caused substantial damage to the cuticle of sedentary plant
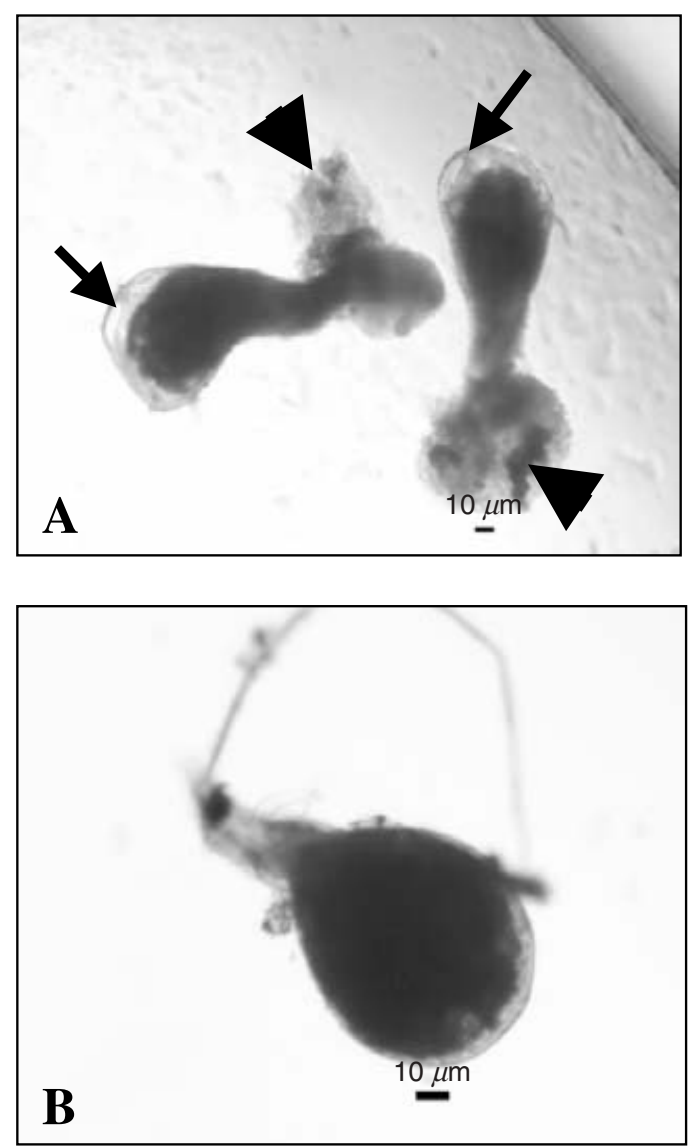

Fig. 7. Light micrographs of Meloidogyne incognita adult female worms incubated with and without papain for $4 \mathrm{~h}$. Digestion of the cuticle was evident for the nematodes incubated with $25 \mu \mathrm{M}$ (active enzyme) papain (A). Note the release of the internal structures (arrowheads) from these nematodes and the cuticle coming away from the worm (arrows). The worms incubated without enzyme (B) had a normal appearance.

parasitic nematodes (Meloidogyne spp. and G. rostochiensis), which resulted in a significant reduction in the activity of their second-stage juveniles. This effect was similar to that described previously for gastrointestinal nematodes of humans and livestock (Robbins, 1930; Berger and Asenjo, 1939; Stepek et al. 2005, 2006, 2007), indicating that plant cysteine proteinases have a broad spectrum of action against parasitic nematodes in vitro. These natural plant products showed efficacy in vitro against Meloidogyne spp., and similar effects were observed using the same concentrations and duration of incubation with papaya latex and papain, but not with stem bromelain, on G. rostochiensis J2s. Preliminary work demonstrated that longer incubation with papain was needed to cause some damage to the cuticle of $G$. rostochiensis; this suggests that there are differences in the cuticle of these nematodes and that rootknot nematodes may be more susceptible to plant cysteine proteinases than potato cyst nematodes. This is probably due to the much tougher cuticle of $G$. rostochiensis second-stage juveniles, which is approximately $0 \cdot 6 \mu \mathrm{m}$ thick (Zunke and Eisenbeck, 
1998), whereas that of Meloidogyne spp. J2s is only approximately $0 \cdot 3-0 \cdot 4 \mu \mathrm{m}$ thick (Eisenbeck, 1985). Further work will be required to investigate this in more detail, but it may be simply that greater enzyme concentrations and/or longer incubation periods are required for potato cyst nematodes to succumb to the detrimental effects of stem bromelain.

It would appear that the mechanism of action of plant cysteine proteinases against animal and plant nematodes is digestion of the cuticle, releasing the internal structures, and leading to death of the parasites. However, the cuticular proteins susceptible to this digestion still remain unknown. The gastrointestinal nematodes of animals are sensitive to the effects of these cysteine proteinases, but are resistant to the effects of aspartic and serine proteinases which are present in the gut. Hence, the absence of cysteine proteinases from the host GI tract means that there is no opportunity to generate resistance to this class of enzyme. In contrast, the nematodes present in the GI tract have developed resistance to the gut proteinases (Stepek et al. 2005), at least in part through the synthesis of inhibitors that do not inhibit cysteine proteinases (Peanasky and Abu-Erreish, 1970). Even the free-living organism, Caenorhabditis elegans, expresses a large number of serine proteinase inhibitors (Zang and Maizels, 2001) that may have provided an evolutionary launch pad for the successful colonization of the vertebrate gut. The susceptibility of the plant nematodes to cysteine proteinases also suggests that they have not yet evolved an effective defence against these enzymes, despite the fact that the enzymes can be retrieved from defensive latices of some plants. Nevertheless, despite the similarity in effects of plant cysteine proteinases against parasitic nematodes of animals and plants, there are distinct differences. For instance, there is a much more rapid effect against animal nematodes (Stepek et al. 2005, 2006, 2007) and there is a lack of efficacy of actinidain against animal nematodes but not against plant nematodes of, at least, the root-knot species; the efficacy of actinidain against potato cyst nematodes is still unclear. The crystal structures of papain and actinidain are closely similar and virtually superimposable in the active-centre; however, there is evidence for differences in the characteristics and behaviour of their catalytic sites (Kowlessur et al. 1989). This indicates that the cuticles of animal and plant nematodes differ and that the susceptible cuticular proteins are likely to be different, based on the differential effect of actinidain on plant and animal nematodes.

Although the cysteine proteinases had nematicidal activity against the $\mathrm{J} 2 \mathrm{~s}$ and adult worms, we found no in vitro effects on the eggs of Meloidogyne spp. The structure of the eggs remained unaffected, even after overnight incubation with papain. This suggests that the components of the cuticle that are sensitive to attack by the cysteine proteinases are only present or exposed to the action of these enzymes in the infective stages and adult worms. This was also observed in the case of the rodent gastrointestinal nematode, Heligmosomoides polygyrus, in that the eggs of this nematode were not affected detrimentally by plant cysteine proteinases, and the structure and development of the L1 stage remained unaffected (Stepek et al. unpublished). A possible explanation for the lack of activity against the eggs is that the eggshell is composed largely of non-proteinaceous chitin, whereas the cuticle of the larval and adult stages is composed largely of collagen (Bird and Bird, 1991).

In conclusion, this is the first time that the nematicidal effect of plant cysteine proteinases has been demonstrated for sedentary plant parasitic nematodes. Further investigation is required to determine whether these plant products are also efficacious against plant nematodes in vivo, and whether these plant enzymes also show efficacy against other species of nematode pests. If this proves to be the case, then some cysteine proteinases from plants may potentially be developed into novel treatments for the control of plant parasitic nematodes. Previous research at Rothamsted has shown that, by affecting nematode motility, we can interfere with infection of plants by nematodes (Fioretti et al. 2002; Sharon et al. 2002; GB Patent Filing 46082). We envisage that the cysteine proteinases examined in this current study will affect nematode motility in vivo and therefore the ability of the nematode to infect its plant host.

This work was funded by a research grant from The Leverhulme Trust held by J.M.B., D.J.B. and I.R. D. Rothamsted Research receives grant-aided support from the Biotechnology and Biological Sciences Research Council of the United Kingdom. We are sincerely grateful to Tim Smith for excellent technical assistance in electron microscopy, and to Ian Mellor (University of Nottingham) for his help in producing the sigmoidal dose-response curve in Fig. 1B.

\section{REFERENCES}

Ahmad, M. S., Mukhtar, T. and Ahmad, R. (2004).

Some studies on the control of citrus nematode (Tylenchus semipenetrans) by leaf extracts of three plants and their effects on plant growth variables. Asian fournal of Plant Sciences 3, 544-548.

Akhtar, M. and Mahmood, I. (1994). Potentiality of phytochemicals in nematode control: a review. Bioresource Technology 48, 189-201.

Berger, J. and Asenjo, C. F. (1939). Anthelmintic activity of fresh pineapple juice. Science 90, 299-300.

Berger, J. and Asenjo, C. F. (1940). Anthelmintic activity of crystalline papain. Science $\mathbf{9 1}, 387-388$.

Bird, A. F. and Bird, J. (1991). The Egg. In The Structure of Nematodes (ed. Bird, A. F.), pp. 7-43. Academic Press, New York.

Chitwood, D. J. (2003). Research on plant-parasitic nematode biology conducted by the United States 
Department of Agriculture - Agricultural Research Service. Pest Management Science 59, 748-753.

Dubois, T., Jacquet, A., Schnek, A. G. and Looze, Y. (1988). The thiol proteinases from the latex of Carica papaya L. I. Fractionation, purification and preliminary characterisation. Biological Chemistry Hoppe-Seyler 369, 733-740.

Eisenbeck, J. D. (1985). Detailed morphology and anatomy of second-stage juveniles, males and females of the genus Meloidogyne (root-knot nematodes). In $A n$ Advanced Treatise on Meloidogyne. Vol. I: Biology and Control (ed. Sasser, J. N. and Carter, C. C.), pp. 47-77. Department of Plant Pathology and the United States Agency for International Development.

Fioretti, L., Porter, A., Haydock, P. and Curtis, R. H. C. (2002). Monoclonal antibodies reactive with secreted-excreted products from the amphids and the cuticle surface of Globodera pallida affect nematode movement and delay invasion of potato plants. International Fournal for Parasitology 32, 1709-1718.

Giday, M., Asfaw, Z., Elmqvist, T. and Woldu, Z. (2003). An ethnobotanical study of medicinal plants used by the Zay people in Ethiopia. Fournal of Ethnopharmacology 85, 43-52.

Hussey, R. S. and Barker, K. R. (1973). A comparison of methods of collecting inocula of Meloidogyne spp. including a new technique. Plant Disease Report 57, 1025-1028.

Kowlessur, D., O’Driscol, M., Topham, M., Templeton, W., Thomas, E. W. and Brocklehurst, K. (1989). The interplay of electrostatic fields and binding interactions determining catalytic-site reactivity in actinidin. The Biochemical Fournal 259, 443-452.

McDowall, M. A. (1970). Anionic proteinase from Actinidia chinensis: preparation and properties of the crystalline enzyme. European Fournal of Biochemistry 14, 214-221.

Meyer, S. L. F. (2003). United States Department of Agriculture - Agricultural Research Service research programs on microbes for management of plant-parasitic nematodes. Pest Management Science 59, 665-670.

Miller, P. M. and Sands, D. C. (1977). Effects of hydrolytic enzymes on plant-parasitic nematodes. Fournal of Nematology 9, 192-197.
Peanasky, R. J. and Abu-Erreish, G. (1970). Inhibitors from Ascaris lumbricoides: interactions with the host's digestive enzymes. In Proceedings of the International Research Conference on Proteinase Inhibitors, Berlin, 1970. pp. 281-293.

Robbins, B. H. (1930). A proteolytic enzyme in ficin, the anthelmintic principle of Leche de Higueron. Fournal of Biological Chemistry 87, 251-257.

Rowan, A. D., Buttle, D. J. and Barrett, A. J. (1990). The cysteine proteinases of the pineapple plant. The Biochemical Yournal 266, 869-875.

Sgarbieri, V. C., Gupte, S. M., Kramer, D. E. and Whitaker, J. R. (1964). Ficus enzymes. I: Separation of the proteolytic enzymes of Ficus carica and Ficus glabrata latices. Fournal of Biological Chemistry 239, 2170-2177.

Sharon, E., Spiegel, Y., Solomon, R. and Curtis, R. H. C. (2002). Characterisation of Meloidogyne javanica surface coat using antibodies and their effect on nematode behaviour. Parasitology 125, 177-185.

Siddiqui, M. A., Haseeb, A. and Alam, M. (1992). Control of plant-parasitic nematodes by soil amendments with latex bearing plants. Indian Fournal of Nematology 22, 25-28.

Stepek, G., Buttle, D. J., Duce, I. R., Lowe, A. and Behnke, J. M. (2005). Assessment of the anthelmintic effect of natural plant cysteine proteinases against the gastrointestinal nematode, Heligmosomoides polygyrus, in vitro. Parasitology 130, 203-211.

Stepek, G., Lowe, A. E., Buttle, D. J., Duce, I. R. and Behnke, J. M. (2006). In vitro and in vivo anthelmintic efficacy of plant cysteine proteinases against the rodent gastrointestinal nematode, Trichuris muris. Parasitology 132, 681-689.

Stepek, G., Lowe, A. E., Buttle, D. J., Duce, I. R. and Behnke, J. M. (2007). Anthelmintic action of plant cysteine proteinases against the rodent stomach nematode, Protospirura muricola, in vitro and in vivo. Parasitology 134, 103-112.

Zang, X. and Maizels, R. M. (2001). Serine proteinase inhibitors from nematodes and the arms race between host and pathogen. Trends in Biochemical Sciences 26, 191-197.

Zunke, U. and Eisenbeck, J. D. (1998). Morphology and ultrastructure. In The Cyst Nematodes (ed. Sharma, S. B.), pp. 31-56. Chapman \& Hall, London. 